\title{
Representações sociais sobre a família do adolescente em conflito com a lei: a lei e suas ressignificações
}

\author{
Juliana Vinuto ${ }^{1}$ \\ Universidade de São Paulo, Sáo Paulo, São Paulo, Brasil
}

DOI: 10.11606/issn.2316-9133.v22i22p326-336

resumo Pretende-se analisar aqui duas diferentes construçôes representacionais sobre a família do adolescente em conflito com a lei: uma encontrada na Doutrina de Proteçáo Integral, que ampara o Estatuto da Criança e do Adolescente (ECA), e outra encontrada em narrativas de implementadores de medida socioeducativa, como psicólogos, assistentes sociais, etc, que atuam em medidas de internação ou liberdade assistida. Tais representações não deveriam ser divergentes, já que o trabalho desses funcionários é guiado pelo ECA, porém, durante a fase de entrevistas de uma pesquisa em andamento verificou-se algumas divergências entre as representaçôes mobilizadas por estas duas instâncias. Objetiva-se problematizar tais representaçôes a partir do trabalho de Lipsky (1983), que observa uma dimensão ressignificada em que mesmo que o âmbito político molde os padróes de decisão, a discricionariedade dos implementadores de ponta pode afetar a qualidade dos benefícios e as sançóes possíveis.

palavras-chave Representaçôes sociais; Implementadores de medidas socioeducativas; Adolescente em conflito com a lei; Doutrina de Proteçâo Integral; Família.

Social representations about adolescents in conflict with the law families: the law and its re-signification

abstract This paper aims at analyzing two different representational constructions about adolescents in conflict with the law families: one based on the Integral Protection Doctrine, which supports the Children and Adolescent Statute (Estatuto da Criança e do Adolescente, ECA); and another one detected in narratives of the socio-educational measures implementers, such as psychologists, social workers etc., who act on internment or probation measures. These representations should not be divergent, since the work of these employees is guided by ECA; however, during the interview stage of an ongoing research, there were some disagreement between the representations mobilized towards the two instances. This paper goal is to problematize these representations from the work of Lipsky (1983), who observes a re-signified dimension in which, even though the political frame mold the decision patterns, the discretion of the (street level) implementers can affect the quality of the benefits and its possible sanctions.

keywords Social representations; Socio-educational measures implementers; Adolescents in conflict with the law; Integral Protection Doctrine; Family.

\section{Introduçáo}

Se propóe problematizar, neste artigo, duas construçôes representacionais sobre a família do adolescente em conflito com a lei, sendo uma encontrada na Doutrina de Proteção Integral $^{2}$, que fundamenta o Estatuto da Criança e do Adolescente (ECA) - e que por sua vez alicerça todas as políticas públicas brasileiras voltadas à população infanto-juvenil -, enquanto que a outra representação social é vi- 
sualizada em narrativas formuladas por alguns implementadores de medida socioeducativa, ou seja, aqueles que executam - e, à sua forma, vivenciam - a puniçâo determinada pelo judiciário ao adolescente nomeado enquanto autor de ato infracional. ${ }^{3}$ Em um primeiro momento seria possível pressupor que tais representaçôes se assemelhariam, já que o trabalho desenvolvido pelos implementadores de medida socioeducativa deve se basear nas diretrizes do ECA, porém, durante pesquisa de campo de mestrado em andamento, verificou-se que tais representaçóes ora se aproximam, ora se afastam, e intenciona-se analisar aqui os pontos de encontro e de desajustes entre ambas.

Nesse contexto, mostra-se importante compreender as representaçóes sociais construídas por um grupo sobre determinado objeto, já que são tais representaçóes que informam os indivíduos sobre o mundo a sua volta, a fim de capacitá-lo a agir frente a coisas e pessoas. É nesse sentido que é possível afirmar que as representações sociais são uma forma coletiva de conhecimento, construídas a partir de trocas e práticas dentro de um determinado contexto histórico, fornecendo subsídios para julgamentos e atitudes, criando um sistema de interpretaçáo e mostrando-se dimensão importante para a compreensão de posturas e significados. As representaçóes sociais são construídas na tentativa de uma formulação consensual da realidade, mas devido a inúmeras formas de contato entre os grupos, estão a todo o momento sendo reorganizadas e aprofundadas. Ao compreender a formação, a potência e as consequências de tais representaçôes é possível elucidar processos cognitivos e interações sociais. Em suma, as representaçóes sociais formam um sistema de interpretação que influencia nossa relação com o mundo, a partir da interiorização de experiências e diálogos, e orientando condutas e comunicaçôes sociais, ou seja, observa-se tal sistema de interpretaçâo tanto enquanto produto como enquanto processo de uma apropriação da realidade, encontrando-se aí tanto as características do objeto construído quanto as do sujeito que constrói tais representações.

Tal dimensão analítica permite visualizar a importância de se estudar as representaçôes sociais sobre a família do adolescente em conflito com a lei, já que tais influenciam os comportamentos perante o adolescente e à sua própria família, tendo peso importante nas interaçóes sociais entre tais grupos e os implementadores de medida socioeducativa, grupo profissional que está em constante contato com tais adolescentes e tem influência sobre a forma que a medida socioeducativa será vivenciada. Neste contexto, vale ressaltar as razóes pelas quais se devem problematizar o lócus ocupado pela família no contexto de execução de uma dada medida socioeducativa, já que a caracterização da mesma tem peso relevante para a caracterização do próprio adolescente em conflito com a lei, como se verá posteriormente.

Muito já se falou sobre o poder socializador ocupado pela instituição familiar, responsável pela transmissão da linguagem, de regras culturais e de valores, dentre outros (BERGER E LUCKMAN, 2011). A família influencia seus membros das formas mais diversas, sendo que a sociedade, de alguma forma, espera que tais membros detenham características em comum, como um prolongamento do meio social no qual vivem. Porém, é necessário lembrar que a ideia de uma família homogênea também é uma construção social, tanto em termos de semelhanças culturais entre seus membros, quanto em termos de características gerais do que seria um modelo de família. Segundo Philippe Ariès (1981), a partir do século XVII ocorrem algumas mudanças importantes, relativas ao contexto social e ao discurso intelectual, que permitiram a cristalização do que atualmente é conhecido como as diferentes fases da vida, como infância, 
adolescência, juventude e velhice. Dentre tais mudanças, é possível citar as novas configuraçóes familiares, a partir de um reordenamento desta quanto ao resto da sociedade, dado que a partir deste momento, o lugar da socialização não se realiza mais no mundo exterior, mas eminentemente no espaço familiar, iniciando-se também um processo de delegação da educação nomeada como formal. Uma das consequências desse contexto foi o fato de a escola tornar-se a forma por excelência de aprendizagem por parte das crianças, o que diminuiu o contato destas com os adultos durante a fase escolar, permitindo uma distinção ainda maior entre o mundo infanto-juvenil e o mundo adulto.

Nesse sentido, mais esclarecedor do que pensar em família seria pensar em famílias. Pensando em extremos, ao mesmo tempo em que a família pode ser o lugar privilegiado de formação e intimidade, também há espaço para despotismos e violências. A depender da forma como se constrói a representação social sobre a família do adolescente em cumprimento de medida socioeducativa - como espaço de suporte ou de opressão - há influências sobre a maneira como este será compreendido e tratado, bem como sobre as explicaçóes que serão dadas ao seu comportamento rotulado como infracional. Este cenário evidencia a importância de debates sobre esta questão, e espera-se, com este trabalho, contribuir para tais discussóes.

Para o desenvolvimento dessa questão se lançou mão de duas técnicas metodológicas, e os dados coletados a partir destas serão expostos aqui. Num primeiro momento, se desenvolverá uma análise sobre a forma que a Doutrina de Proteção Integral se apresenta no ECA, com foco nos pontos relativos à família do adolescente - não necessariamente em conflito com a lei, mas que estende-se a este. Posteriormente, se apresentará algumas narrativas coletadas a partir de entrevistas semi-estruturadas, reali- zadas com alguns implementadores de medida socioeducativa, especificamente no que tange às famílias dos adolescentes em conflito com a lei. Acredita-se que tais métodos permitirão problematizar as diferentes lógicas que perpassam os atendimentos realizados pelos implementadores de medida socioeducativa junto a este adolescente, bem como a relação social produzida a partir desses. Tratam-se de psicólogos, sócio-educadores, assistentes sociais, etc., que interagem cotidianamente com este adolescente e cujas representaçôes sociais sobre o mesmo influenciam o tipo de relação social que será construída durante a execução desta forma de punição. Em suma, a compreensão da relação entre este implementador de medida socioeducativa e o adolescente nomeado enquanto autor de determinado ato infracional é considerada fundamental para o entendimento da construção social do grupo definido, após a promulgaçấo do Estatuto da Criança e do Adolescente (ECA) como adolescentes em conflito com a lei, sendo importante compreender em que medida tais funcionários reproduzem, requalificam ou inovam as classificações advindas das normativas que regulam seu trabalho. Dessa forma, intenciona-se analisar as formas que tais narrativas se opóem e/ou se aproximam da Doutrina da Proteção Integral que, de alguma forma, influencia os trabalhos possíveis de serem realizados por estes funcionários em relação ao adolescente em conflito com a lei.

Acredita-se que, além de analisar o que propõem os formuladores de políticas, mostra-se importante também verificar como as políticas públicas e leis são executadas na ponta do processo de atendimento à população, e para analisar as possíveis ressignificações realizadas entre o que diz a letra da lei e a maneira como ela é vivenciada pelos atores se lançará mão da abordagem de Michael Lipsky (1983), que trabalha justamente as adaptaçóes neces- 
sárias para a implementação de qualquer política pública durante as interaçóes cotidianas vivenciadas por estes funcionários-executores. Por fim, se tecerá alguns comentários a fim de problematizar como alguns estudos antropológicos podem iluminar questóes que perpassam o problema de pesquisa aqui proposto.

\section{A família na doutrina da proteçáo integral}

\begin{abstract}
A criança e o adolescente gozam de todos os direitos fundamentais inerentes à pessoa humana, sem prejuízo da proteçáo integral de que trata esta Lei, assegurando-se-lhes, por lei ou por outros meios, todas as oportunidades e facilidades, a fim de lhes facultar o desenvolvimento físico, mental, moral, espiritual e social, em condições de liberdade e de dignidade (Estatuto da Criança e do Adolescente, artigo 3).
\end{abstract}

A Doutrina da Proteção Integral, sintetizada no artigo 23 da Constituição Federal de 1988 e posteriormente regulamentada através da promulgação do ECA em 1990, é o pressuposto normativo de que crianças e adolescentes devem ser concebidos a partir de seu valor intrínseco como seres humanos, enquanto cidadáos plenos e sujeitos à proteção prioritária, tanto da sociedade quanto do Estado, sendo população preferencial no que tange ao uso de recursos públicos, a fim de garantir a efetivação da proteção voltada a esse grupo. Nesse sentido, a Constituição Federal e o ECA elevam a criança e o adolescente à condição de sujeitos de direitos, e a proteção integral volta-se a um grupo de indivíduos em processo de desenvolvimento físico, psicológico e moral, sendo a partir de tais aspectos do desenvolvimento humano merecedores de cuidado total.
Verifica-se que o texto do ECA está atravessado sobre o que se considera Proteção Integral, indicando que à todas as crianças e adolescentes são indistintamente direcionados os direitos fundamentais do ser humano, bem como a necessidade de protegê-las de qualquer forma de negligência, discriminação, exploração, violência, crueldade e opressão. Por isso, à população infanto-juvenil devem ser destinadas políticas específicas que a proteja nestes aspectos, sendo que a defesa das dimensóes implicadas neste contexto deve ser realizada também integralmente, ou seja, com o suporte do Estado, da sociedade em geral e da família dessas crianças e adolescentes, o que acarreta a tese de que o ato infracional cometido está relacionado, dentre outras coisas, também à falta de êxito dessas instituiçôes em socializar o adolescente de forma a se distanciar de atos ilícitos. ${ }^{4}$ Porém, apesar de na letra da lei existir esse círculo de proteção integral entre Estado, sociedade e família, no próximo capítulo se verificará que há espaços nos quais apenas a família é responsabilizada.

\section{A família nas narrativas dos implementadores de medida socioeducativa}

Claro que tem (problema) de família, com a família totalmente desestruturada, com o pai alcoólatra que bate no filho, a mãe mesmo pede para o menino sair para conseguir dinheiro, que fica vivendo a partir de tráfico, de roubo, essas coisas (Entrevista com agente de apoio socioeducativo de medida de internação, realizada em 14/03/13).

Apesar do ECA ser perpassado pela Doutrina de Proteção Integral, durante a fase de entrevistas de um mestrado em andamento com funcionários de medida socioeducativa, tanto restritivas de liberdade quanto em meio 
aberto, observou-se espaços para narrativas de culpabilização da família. Durante essas entrevistas raramente se contestou as possibilidades da ação do Estado e da sociedade em assegurar os direitos desses adolescentes, enquanto que observações sobre a família frequentemente foram tecidas, usualmente no sentido de explicar o comportamento infracional do adolescente, bem como suas possibilidades de desvincular-se da criminalidade. Nesse sentido, é expressiva a fala de uma entrevistada sobre as razóes para a centralidade de avaliaçốes sobre a família:

$\mathrm{O}$ adolescente tem a responsabilidade dele, enquanto cumprimento da medida, e a família tem a responsabilidade também, de dar o suporte, de fazer o papel dela enquanto família, que é aquela proposta de trabalho, de participação em grupo, verificar a matrícula na escola, etc. ${ }^{5}$

Neste âmbito, ainda que as medidas socioeducativas estejam permeadas com as premissas da Proteção Integral - já que a dimensão da punição está perpassada na ideia de ressocialização - nas narrativas desses implementadores de medida socioeducativa é possível visualizar mais claramente a dimensão da necessidade de maior controle estatal sobre as famílias, passível de ser realizado devido ao pressuposto de que a culpa pelo comportamento infracional do adolescente está na falta da responsabilidade de sua família quanto à sua socialização, como é possível visualizar na seguinte fala:

Então temos que trabalhar tudo isso, trazer à tona essa responsabilidade que é da família. $\mathrm{O}$ menino está emprestado para nós, e ele vai regressar, então se a gente não mexer nesse núcleo, é praticamente certo que o menino vai retornar para a mesma batida que ele vinha antes. Entáo precisamos mexer nisso, preparar a mãe - principalmente a mãe, que é a maior batalhadora nesse sentido. ${ }^{6}$
Aqui é possível visualizar que o controle exercido sobre a família é ainda mais potente no que se refere ao comportamento da mãe do adolescente. $\mathrm{Na}$ imensa maioria das vezes, o fato do pai ou outros parentes não acompanharem a medida de seu filho raramente é questionada, enquanto que a falta de frequência da mãe em visitas e atendimentos indicam, direta ou indiretamente, problemas familiares. Tal postura considerada displicente da mãe, inclusive, é encarada como uma das razôes para a infração de seu filho. Uma das explicações ouvidas para tal divisão refere-se a supostas características intrínsecas das mulheres: $E$ aquela coisa, é amor incondicional, eu vejo que é da coisa da mulher essa questão de acolhimento, aquela coisa maternal. ${ }^{7}$ Observa-se uma dimensão de culpabilização na qual, o que na letra da lei nomeia-se como proteção integral a ser realizada por diversas instituiçóes, nas relaçóes cotidianas desses implementadores é visualizada como a solitária atuação da mãe na proteção de seu filho, já que muitas vezes não se considera as chances reais dessa mãe utilizar-se de serviços públicos ou de apoiar-se em outros âmbitos da sociedade ou de sua própria família para efetuar a tâo desejada proteção integral.

Porém, nada que se refira à prática dos atores pode ser considerado como determinado ou homogêneo. Apesar de não ser a regra, existe sempre a possibilidade desses implementadores de medida socioeducativa realizar problematizaçóes que vão além da punição sobre as relaçôes familiares do adolescente nomeado enquanto em conflito com a lei. $\mathrm{Na}$ seguinte explicação sobre o peso da estrutura familiar sobre o comportamento do adolescente, é possível visualizar a dimensão da responsabilidade estatal na proteçáo integral do adolescente e de sua família, percebendo-a como fator importante na possibilidade que as famílias têm de cuidar das crianças e adolescentes de seu núcleo: $O$ que existe é uma familia desestruturada 
pelo Estado. ${ }^{8} \mathrm{Na}$ narrativa completa deste implementador também se poderá perceber o peso da família na ressocialização deste adolescente, porém aqui é problematizado o papel estatal em fornecer subsídios para que esta família possa cumprir seu papel ressocializador, não apenas em termos de controle, mas também em termos de possibilidades de utilização de serviços públicos para a execução dessa tarefa.

Tais narrativas parecem adequar-se aos trabalhos empíricos sobre as atribuiçóes que a família do adolescente em conflito com a lei parece deter durante a execução da medida socioeducativa. Paula (2004) ressalta que, tanto o adolescente como sua família são encarados como "suspeitos" por uma associação não declarada com o ato de infringir a lei, criando-se uma ligação entre o ato infracional cometido pelo adolescente e a negligência de sua família em evitar o mesmo. Porém, as percepçóes sobre o peso das relações familiares do adolescente em medida socioeducativa não se constrói da mesma forma para todos os diferentes implementadores de medida socioeducativa, como é exposto pela autora (2004, p. 23):

Os responsáveis pela manutenção da segurança, os monitores e encarregados de ala, mantêm as relaçôes familiares no registro das "relaçôes perigosas" que associam o adolescente ao ato infracional. Assim, enfatizam a violência doméstica, o abandono, a falta de apoio e de condiçóes financeiras dos pais como características dos adolescentes internados.

Por outro lado, há outras percepções possíveis a serem construídas por estes funcionários:

Já os funcionários do grupo técnico - pedagogos, assistentes sociais e psicólogos responsáveis pela dimensão pedagógica da internação - vão além de apontar essa "periculosidade" da família, relacio- nando-a como algo que a instituiçáo deva tratar. Nesse sentido, a família não somente é inserida naquele conjunto de relaçôes associadas ao ato infracional do internado, como também passa a integrar a atuação pedagógica sobre o adolescente.

Tais exposições permitem afirmar que há um distanciamento no que se refere aos pressupostos da Doutrina de Proteção Integral, no qual durante a implementação da medida socioeducativa há uma dimensão culpabilizadora da família, em especial da mãe, em detrimento das açôes passíveis de serem realizadas pelo Estado e pela sociedade. Nesse sentido, vale lembrar que a discussão aqui não está presa ao "dever ser" da prática profissional desses trabalhadores, mas visa compreender de que forma a prática da Doutrina de Proteção Integral é vivenciada pelos implementadores de medida socioeducativa. No âmbito da ação desses implementadores formulam-se teorias, baseadas na prática e no senso comum, ${ }^{9}$ que tenta explicar o comportamento infracional do adolescente através de sua rede de contatos mais próxima, que estaria falhando na criação deste adolescente. Nesse sentido, necessita-se avaliar o espaço de discricionariedade desses atores que atuam na ponta do processo de implementação da medida socioeducativa, já que tal discricionariedade permite a ressignificação das diretrizes que permeiam o trabalho desses atores, influenciando sobremaneira a relação social construída e os benefícios e sanções possíveis de serem executados.

\section{Discussóes possíveis}

In short, they hold the keys to a dimension of citizenship (LIPSKY, 1983, p. 4).

Apesar de a Doutrina de Proteçáo Integral envolver o trinômio Estado-sociedade-família, percebe-se que há uma ressignificação ${ }^{10}$ dessa 
normativa pelos implementadores das políticas voltadas ao adolescente em cumprimento de medida socioeducativa no que se refere à responsabilização da mãe do adolescente, em detrimento das outras esferas responsáveis. A partir deste contexto mostra-se importante compreender o processo de ressignificação desses implementadores que, por estarem na ponta do processo de atendimento, são mais intensamente influenciados pelas interaçóes cotidianas com tais adolescentes e com suas famílias, evidenciando um espaço de prática que informa, de alguma maneira, as representaçóes sobre a família do adolescente construídas por estes funcionários.

$\mathrm{O}$ interesse em trabalhar as representaçóes sociais construídas pelos implementadores de medida socioeducativa se dá porque mesmo que o âmbito político molde seus padróes de decisão, a discricionariedade necessária para a realização de seu trabalho pode afetar a qualidade dos benefícios e as sançôes possíveis junto ao adolescente em conflito com a lei. Para analisar tal situação, mostra-se útil lançar mão do aparato conceitual formulado por Lipsky (1983) no que se refere à street-level bureaucracy, devido à centralidade que dá à atuaçáo da burocracia que trabalha ao final do processo de implementação no que se refere aos efeitos e resultados de uma dada política pública. Dessa forma, apesar da estrutura de poder que limita seu trabalho, os burocratas de nível de rua lançam mão de discricionariedade a fim de desenvolver suas tarefas cotidianas de acordo com as demandas existentes, podendo atuar com aversão ou empatia e acarretando em complexas interaçôes que podem afetar diretamente as sançóes e os benefícios recebidos pela população.

As interaçôes com os integrantes da street-level bureaucracy - no caso desse trabalho, especificamente com os implementadores de medida socioeducativa - são momentos através dos quais os cidadãos experimentam diretamen- te o governo, implicitamente construído, já que tal burocracia tem o papel de "ser o Estado", no sentido de personificar os direitos e deveres desta população. Segundo Lipsky (1983), uma das características do trabalho desses implementadores é que as interaçóes de seu cotidiano de trabalho usualmente são construídas a partir de uma base conflituosa, dado que o público alimenta expectativas que tais funcionários não têm possibilidade de atender. Além disso, outro ponto que complexifica esta relação é o fato de que as pessoas que tornam-se o foco de uma política têm necessidades e perfis muito específicos, enquanto que os implementadores de ponta só conseguem realizar o seu trabalho ao transformá-las a partir de padróes indiferenciados.

Por fim, vale pontuar que além das relações potencialmente conflituosas entre as partes citadas, o trabalho dos implementadores de ponta também é influenciado por outras dimensôes. Para citar apenas um, enquanto indivíduos posicionados acima destes na cadeia hierárquica de uma política, como políticos e administradores, tem a possibilidade de abordar determinados problemas sociais em nível abstrato, os diversos tipos de implementadores confrontam-se cotidianamente com tais problemas na prática. Tal relação é fonte inesgotável de críticas realizadas por estes implementadores sobre o trabalho de seus superiores, pois o consideram como distanciados da realidade, o que pode facilitar a desobediência das diretrizes propostas e a adaptação das mesmas às demandas cotidianas.

Tal pano de fundo teórico pode ajudar a compreender as ressignificaçóes realizadas pelos implementadores de medida socioeducativa no que se refere à centralidade da atuação da mãe no comportamento infracional do adolescente em conflito com a lei. Durante a fase de entrevista da pesquisa citada pôde-se observar que a representação social de famí- 
lia mobilizada por este grupo, centralizada no papel da mãe, é ligada a uma suposta falta de autoridade e hierarquia devido à ausência da figura paterna, o que seria de grande influência para o comportamento infracional do adolescente. Nesse sentido, verifica-se uma clara divisão sexual do trabalho familiar, na qual a hierarquia deve ser provida pelo pai, enquanto o cuidado mostra-se dever da mãe. Porém, a lógica dessa divisão desconsidera o fato de que, cada vez mais, é a mãe a principal - e às vezes, a única - responsável por suprir as necessidades econômicas, sociais e afetivas dos filhos (SARTI, 2004) e que, portanto, é uma figura sobrecarregada de responsabilidades, tanto no âmbito familiar quanto no social. Além disso, desconsidera-se os muitos outros adolescentes que, mesmo não tendo a suposta figura de autoridade, centralizada no pai, não se envolvem em atos considerados ilícitos, o que pode demonstrar que a figura materna também pode prover a tal almejada autoridade.

Além das pressóes sociais sobre essa mãe, da mesma forma que o adolescente deve atender às expectativas do implementador de medida socioeducativa quanto ao comportamento e a aceitação das propostas da medida, a família - personificada na imagem da mãe - também deve ter a mesma atitude, sendo tal comportamento muitas vezes classificado em termos de família desestruturada ou normal, tendo grandes impactos sobre a classificação dada ao próprio adolescente, já que o mesmo teria maiores dificuldades em se afastar do mundo do crime ${ }^{11}$ nesta situação. Essa ligação entre o ato infracional e a falha familiar na inculcação de valores é muito mais fácil de ser visualizada do que a displicência do Estado e da sociedade no que tange às oportunidades do adolescente em conflito com a lei, já que as ligaçôes entre o ato do adolescente e tais instituiçôes são mais abstratas. E, de forma ainda mais clara, a fa- lha familiar é personificada na imagem da mãe que, além de muitas vezes estar inserida em famílias monoparentais e, portanto, ser a única responsável pelas necessidades financeiras e afetivas de seus filhos, também está inserida numa sociedade que delega a criação dos filhos à mulher, o que facilita ainda mais essa ligação. Como argumenta Nakano (2003, p. 357):

Em nossa sociedade, a maternidade é socialmente valorizada e instituída como responsabilidade/ dever da mulher pelo cuidado com o filho, o que está em parte fundamentada na capacidade que ela tem de engravidar, parir e amamentar e em construçôes sociais de serem as mulheres mais ternas, carinhosas e habilidosas para cuidar da prole.

\section{Comentários finais}

Olhar as dimensões simbólicas da ação social - arte, religiấo, ideologia, ciência, lei, moralidade, senso comum - não é afastar-se dos dilemas existenciais da vida em favor de algum domínio empírico de formas não-emocionalizadas; é mergulhar no meio delas. (GEERTZ, 1989, p. 41).

Como pode-se verificar nos argumentos citados, uma das formas possíveis de se compreender a ressignificação da Doutrina de Proteção Integral frente aos adolescentes em conflito com a lei é analisar a atuação dos implementadores de medida socioeducativa, inseridos na ponta do processo de execução das políticas públicas, atuação essa que é informada pelas representaçóes sociais construídas por este grupo social sobre diversas questôes. No escopo deste trabalho, focou-se sobre as representaçôes sociais sobre as famílias desses adolescentes.

Enquanto que na letra da lei se trata de um círculo de proteção integral a ser realizada pelo Estado, sociedade e família, nas narrativas dos 
implementadores de medida socioeducativa percebe-se que, como Sahlins (1990) já argumentara, a ação dos atores não se conforma necessariamente aos significados que grupos específicos lhes atribuem: "Os homens em seus projetos práticos e em seus arranjos sociais, informados por significados de coisas e de pessoas, submetem as categorias culturais a riscos empíricos" (idem, p. 9). Em tal contexto, para explicar o comportamento infracional do adolescente, tais atores formulam teorias de senso comum, baseados em sua rotina cotidiana, baseadas na materialidade das relaçóes familiares, em detrimento da abstração das relaçóes com o Estado e a sociedade. Tal materialidade, que cristaliza-se na posição ocupada pela mãe, muitas vezes é vista como a explicação para o comportamento infracional do adolescente, bem como para as possibilidades do mesmo em se afastar do mundo do crime, tendo peso considerável na construção social desse adolescente realizada cotidianamente por estes implementadores de medida socioeducativa.

Nesse sentido, é bom lembrar que, como argumenta Geertz (1989), os sistemas culturais não necessitam ser necessariamente coerentes para serem considerados válidos. Por mais que haja debates sobre a necessidade de família, Estado e sociedade desenvolverem açóes próprias, além de apoiarem a figura materna na socialização de seu filho, a rotina diária de trabalho, a relação com adolescentes específicos e suas respectivas famílias, bem como outras diversas esferas, informam o implementador de medida socioeducativa sobre o peso da mãe no comportamento infracional do adolescente considerado em conflito com a lei. A partir deste contexto mostra-se necessário não apenas formular uma política pública, mas também fazer com que os agentes finais do processo de atendimento concordem com os princípios desta, além de ter conhecimento e treinamento em como aplicar adequadamente a mesma, a fim de que seus valores individuais distorçam minimamente as atuações necessárias. Obviamente, as representaçôes sociais sobre a família do adolescente em medida socioeducativa, bem como diversas outras dimensôes, influenciarão as percepçóes e atitudes desses implementadores, porém, mostra-se necessário que a Doutrina de Proteção Integral informe, de alguma forma, tais representaçóes, já que tais funcionários tem maior capacidade de definição da situação frente a esses adolescentes. Acredita-se que as medidas socioeducativas, com foco de fato na Doutrina de Proteção Integral - o que deve ser incentivado pela equipe dirigente das instituiçóes que desenvolvem os trabalhos socioeducativos - exercem menor culpabilizaçáo da família/mãe do adolescente em conflito com a lei, o que viabiliza ações menos opressoras por parte do Estado sobre esses grupos sociais.

\section{Notas}

1. Graduada em Ciências Sociais e mestranda em Sociologia, ambos pela Universidade de São Paulo (USP). É pesquisadora do Núcleo de Antropologia do Direito (NADIR).

2. Em <http://www.unicef.org/brazil/pt/resources_10120. htm> é possível visualizar algumas normativas formuladas pelas Organização das Nações Unidas (ONU) que utilizam-se desta doutrina e a aprofundam, como: Declaração de Genebra de 1924 sobre os Direitos da Criança, Declaração dos Direitos da Criança de 1959, Pacto Internacional de Direitos Civis e Políticos, no Pacto Internacional de Direitos Econômicos, Sociais e Culturais, nas Regras Mínimas das Nações Unidas para a Administração da Justiça e da Juventude, dentre outros.

3. Verificada a ocorrência de um ato infracional - ou seja, a conduta descrita como crime ou contravenção penal, desde que realizada por jovens menores de 18 anos, já que, por serem inimputáveis penalmente, devem ser julgados num fórum de justiça especial -, a autoridade competente poderá aplicar ao adolescente uma das medidas socioeducativas determinadas 
no próprio ECA, a saber: advertência, obrigação de reparar o dano, prestaçáo de serviço à comunidade, liberdade assistida (sendo estas medidas socioeducativas de caráter aberto), semiliberdade e internação (sendo estas medidas restritivas de liberdade). Segundo o Sistema Nacional de Atendimento Socioeducativo (SINASE) tais medidas tem por objetivo: 1) responsabilização do adolescente quanto às consequências lesivas do ato infracional, sempre que possível incentivando a sua reparação; 2) a integraçáo social do adolescente e a garantia de seus direitos individuais e sociais, por meio do cumprimento de seu plano individual de atendimento; e 3) a desaprovaçáo da conduta infracional, efetivando as disposições da sentença como parâmetro máximo de privação de liberdade ou restrição de direitos, observados os limites previstos em lei.

4. Alguns trabalhos já indicaram que, em termos de políticas públicas, a responsabilização sobre a família deste adolescente mostra-se muito mais potente se comparada com a responsabilização do Estado e da sociedade, como em Paula (2004). Segundo a autora, se normativamente ressalta-se que o Estado e toda a sociedade são também responsáveis pela proteção integral desse grupo, verifica-se que a "situação de risco da pessoa em desenvolvimento náo pode ser solucionada sem que se considerem suas relaçôes familiares" (PAULA, 2004, p. 50, grifos no original). Nesse sentido, a família é vista como grupo social significativo para a formação de crianças e adolescentes de seu seio, e por isso também é alvo de diversas políticas públicas voltadas para a proteção dos interesses de crianças e adolescentes, já que o fracasso da socialização destes tende a ser ligada muito mais à família do que à atuação da sociedade e do Estado. Consequentemente, além de intervir no adolescente, considerado enquanto autor de ato infracional, as medidas socioeducativas também intervém nas relaçôes familiares desses adolescentes, de certa forma culpabilizando-as, já que em casos de não-efetivação destes direitos há a responsabilização - implícita ou não - da família do adolescente - e apenas dela - no que se refere à situação vivenciada pelo adolescente.

5. Entrevista com assistente social de medida socioeducativa em meio aberto, realizada em 02/03/13.

6. Entrevista com psicóloga de medida socioeducativa de internação, realizada em 26/07/13.

7. Entrevista com assistente social de medida socioeducativa em meio aberto, realizada em 02/03/13.
8. Entrevista com orientador de medida socioeducativa em meio aberto, realizada em 15/03/13.

9. Considerado não em seu sentido pejorativo, mas de forma semelhante à de Berger e Luckmann (2011), que argumentam que o conhecimento do senso comum "constitui o tecido de significados sem o qual nenhuma sociedade poderia existir" (BERGER E LUCKMANN, 2011, p. 29). Os autores chamam a atenção para a relevância de pesquisas que abordem as maneiras de como se dá o movimento dialético entre o homem e seu mundo, entre o conhecimento que o homem tem e o saber prático cotidiano que a vida em sociedade lhe proporciona, permitindo evidenciar a racionalidade da crença coletiva, mostrando o sentido das ideologias, dos saberes populares e do senso comum, entendendo-os como sistema coerente de signos.

10. Tais ressignificaçóes não ocorrem apenas no âmbito de ação dos implementadores finais de uma dada política pública, mas durante todo o processo de formulação e execução da mesma. Nesse sentido, mostra-se importante estudar a atuação de quem está na ponta desse processo de atendimento, já que as diretrizes que permeiam seu trabalho já passaram por diversas modificaçóes e, ao final, o funcionário que lida diretamente com as pessoas afetadas por este processo deve atuar considerando tanto tais diretrizes já ressignificadas quanto as demandas que emergem a partir das interaçóes com a população afetada, complexificando ainda mais o processo de implementação de uma dada política.

11. Sempre que se lançar mão do termo "mundo do crime”, se utilizará como referência Feltran (2008): "Trata-se de expressão que designa o conjunto de códigos sociais, sociabilidades, relaçóes objetivas e discursivas que se estabelecem, prioritariamente no âmbito local, em torno dos negócios ilícitos do narcotráfico, dos roubos, assaltos e furtos".

\section{Referências bibliográficas}

ARIÉS, Philippe. História social da criança e da família. Rio de Janeiro: LTC, 1981.

BERGER, Peter L., LUCKMANN, Thomas. A construção social da realidade: tratado de sociologia do conhecimento. Petrópolis: Vozes, 2011.

BRASIL. Estatuto da Criança e do Adolescente (ECA). Lei 
336 | Juliana Vinuto

8.096, de 13 de julho de 1990.

Sistema Nacional de Atendimento Socioeducativo (Sinase). Lei no 12.594, de 18 de janeiro de 2012.

Constituição da República Federativa do Brasil de 1988.

FELTRAN, Gabriel de Santis. 2008. Fronteiras de tensão: um estudo sobre política e violência nas periferias de São Paulo. Tese de doutorado em Ciências Sociais. Campinas: IFCH/Unicamp.

GEERTZ, Clifford. A interpretação das culturas. Guanabara Koogan: Rio de Janeiro, 1989.

LIPSKY, Michael. Street-level bureaucracy: dilemmas of the individual in public services. Russell Sage Foundation: New York, 1983.

NAKANO, Ana N. S. As vivências da amamentação para um grupo de mulheres: nos limites de ser "o corpo para o filho" e de ser "o corpo para si”. In: Caderno de Saúde Pública, Rio de Janeiro, 19 (Sup. 2): p. 355-363, 2003.

autora Juliana Vinuto

Mestranda em Sociologia / USP

Recebida em 25/11/2013

Aceita para publicação em 16/12/2013
ORGANIZAÇÃO DAS NAÇÓES UNIDAS. Convenção sobre os Direitos da Criança de 1989. http://www. unicef.org/brazil/pt/resources_10120.htm, último acesso em 28.07.13.

PAULA, Liana de. A família e as medidas socioeducativas: a inserção da familia na socioeducação dos adolescentes autores de ato infracional. Dissertação (Mestrado em Sociologia) - Faculdade de Filosofia, Letras e Ciências Humanas, Universidade de São Paulo, São Paulo, 2004.

Liberdade assistida: punição e cidadania na cidade de São Paulo. Tese (Doutorado em Sociologia) Faculdade de Filosofia, Letras e Ciências Humanas, Universidade de São Paulo, São Paulo, 2011.

SAHLINS, Marshall. Ilhas de História. Rio de Janeiro: Jorge Zahar Editor, 1990.

SARTI, Cynthia. O jovem na família: o outro necessário. In: NOVAES, Regina; VANUCHI, Paulo (Orgs.). Juventude e Sociedade: trabalho, educação, cultura e participação. São Paulo: Fundação Perseu Abramo, 2004. p. 115-29. 